\title{
Thermal evolution of life history and heat tolerance during range expansions toward warmer and cooler regions
}

\author{
José Antonio Carbonell ${ }^{1,2,3}$ and Robby Stoks ${ }^{1}$ \\ ${ }^{1}$ Laboratory of Evolutionary Stress Ecology and Ecotoxicology, University of Leuven, Charles Deberiotstraat 32, Leuven B-3000 \\ Belgium \\ ${ }^{2}$ Department of Wetland Ecology, Doñana Biological Station (EBD-CSIC), Avenida Américo Vespucio 26, Isla de la Cartuja, Seville \\ 41042 Spain
}

Citation: Carbonell, J. A., and R. Stoks. 2020. Thermal evolution of life history and heat tolerance during range expansions toward warmer and cooler regions. Ecology 00(00):e03134. 10.1002/ecy.3134

Abstract. Species' range edges are expanding to both warmer and cooler regions. Yet, no studies directly compared the changes in range-limiting traits within the same species during both types of range expansions. To increase our mechanistic understanding of range expansions, it is crucial to disentangle the contributions of plastic and genetic changes in these traits. The aim of this study was to test for plastic and evolutionary changes in heat tolerance, life history, and behavior, and compare these during range expansions toward warmer and cooler regions. Using laboratory experiments we reconstructed the thermal performance curves (TPCurves) of larval life history (survival, growth, and development rates) and larval heat tolerance (CTmax) across two recent range expansions from the core populations in southern France toward a warmer (southeastern Spain) and a cooler (northwestern Spain) region in Europe by the damselfly Ischnura elegans. First-generation larvae from field-collected mothers were reared across a range of temperatures $\left(16^{\circ}-28^{\circ} \mathrm{C}\right)$ in incubators. The range expansion to the warmer region was associated with the evolution of a greater ability to cope with high temperatures (increased mean and thermal plasticity of CTmax), faster development, and, in part, a faster growth, indicating a higher time constraints caused by a shorter time frame available for larval development associated with a transition to a greater voltinism. Our results thereby support the emerging pattern that plasticity in heat tolerance alone is inadequate to adapt to new thermal regimes. The range expansion to the cooler region was associated with faster growth indicating countergradient variation without a change in CTmax. The evolution of a faster growth rate during both range expansions could be explained by a greater digestive efficiency rather than an increased food intake. Our results highlight that range expansions to warmer and cooler regions can result in similar evolutionary changes in the TPCurves for life history, and no opposite changes in heat tolerance.

Key words: countergradient variation; heat tolerance; range expansions; thermal evolution; thermal performance curves.

\section{INTRODUCTION}

Trait changes associated with range expansions, particularly evolutionary trait changes, have been understudied, yet are pivotal to advance our still nascent mechanistic understanding of contemporary range expansions (Diamond 2018) and our ability to forecast them (Valladares et al. 2014, Bush et al. 2016, Nadeau and Urban 2019). The success of range expansions is indeed determined by evolutionary trait changes to deal with the new selective environments encountered in the invaded areas (Andrade-Restrepo et al. 2019, Lee-Yaw et al. 2019). This trait evolution may not only result from standing genetic variation or de novo mutations, but also from adaptive trait introgression from species

Manuscript received 3 April 2020; revised 8 May 2020; accepted 8 June 2020. Corresponding Editor: Tony D. Williams.

${ }^{3}$ E-mail: jcarbonell@ebd.csic.es already living in and adapted to the invaded areas (Sánchez-Guillén et al. 2016, Wellenreuther et al. 2018). The latter mechanism to acquire beneficial alleles may be widespread as range expansion may create new areas of geographic overlap between formerly allopatric species that may show incomplete reproductive barriers (Sánchez-Guillén et al. 2016). An important aspect of the new environments encountered during range expansions are the thermal regimes (Dudaniec et al. 2018, Sherpa et al. 2019, Van Boheemen et al. 2019). Disentangling the contributions of thermal plasticity and evolution, including the evolution of thermal plasticity, in causing variation in range-limiting traits during range expansions is therefore identified as a research priority (Diamond 2018, Kelly et al. 2019). This asks for common-garden experiments at different temperatures, which has rarely been done for core and edge populations across range expansions (but see, e.g., Crozier 2004, Kolbe et al. 2010). 
Thermal tolerance is a crucial performance trait that is widely acknowledged as a range-limiting trait for aquatic ectotherms (Sunday et al. 2012). Recent insights indicate that during poleward range expansions, species do not just track their "thermal envelope," and therefore can encounter and may need to adapt to novel thermal conditions (Lancaster et al. 2015, Dudaniec et al. 2018). Changes in thermal tolerance are likely as important during range expansions in other directions, like eastwest range expansions (Lenoir and Svenning 2015). Range expansions to warmer regions may be expected to result in the evolution of a higher heat tolerance in freshwater ectotherms given they show a general pattern of higher heat tolerance at warmer latitudes (Sunday et al. 2019). For example, the water flea Daphnia magna has a higher heat tolerance at warmer, lower latitudes in Europe (Seefeldt and Ebert 2019). Such patterns can evolve rapidly: D. magna evolved a higher heat tolerance in response to $2 \mathrm{yr}$ of experimental warming (Geerts et al. 2015). On the other hand, the emerging pattern is that range expansions toward cooler regions do not result in a change in heat tolerance, likely because of a release from selection on this trait (Lancaster 2016).

Besides heat tolerance, life history traits are also expected to change during range expansions to adjust to the new thermal conditions (Parkash et al. 2013). Moreover, both types of traits may interact (Thompson et al. 2017). During range expansions of insects toward warmer regions, an increase in voltinism (more generations per year) can be expected based on the widespread increases in voltinism at warmer latitudes (Zeuss et al. 2017) and under global warming (Matsuda et al. 2018). This higher number of generations per year may result in increased time constraints caused by a shorter time frame available for larval development per generation (Shama et al. 2011). Life history theory predicts faster development rates under short development time stress (Rowe and Ludwig 1991, Abrams et al. 1996), most likely associated with faster larval growth rates to avoid a reduction in body mass at metamorphosis (Abrams et al. 1996). Note that development rate and growth rate are two different life history traits that can respond differently to environmental conditions (e.g., Lind and Johansson 2011, Janssens and Stoks 2018). While development refers to the rate at which organisms go through developmental stages, growth refers to the increase in mass over time (Van der Have and de Jong 1996). Intriguingly, moving to colder regions may also result in faster development and growth rates because of countergradient variation where populations evolve a faster life history through selection imposed by the stronger time constraints in cooler environments (Conover et al. 2009, Tüzün and Stoks 2018). Countergradient variation occurs when selection results in genetic adaptation that counteracts environmental effects such that a similar phenotype is maintained across environments (Levins 1968, 1969, Eckhart et al. 2004). Despite the many range expansions toward regions with different thermal environments (Chen et al. 2011, Lenoir and Svenning 2015), no studies reported species showing range expansions toward both warmer and cooler regions. As a result, no studies directly compared within the same species whether range expansions toward warmer and cooler regions resulted in similar changes of life history, yet different changes for heat tolerance.

The aim of this study is to test for plastic and evolutionary changes in heat tolerance and life history and compare these between range expansions toward warmer and cooler regions in the damselfly Ischnura elegans. For this, we carried out a common-garden experiment where larvae were reared at a range of temperatures to reconstruct (the evolution of) the thermal performance curves for life history (survival, growth, and development rates) and heat tolerance. To mechanistically understand changes in growth rate, we additionally studied food intake and digestive physiology. We expected the evolution of a faster life history (both faster development and growth rates) during range expansions to (1) a cooler region because of countergradient variation (Conover et al. 2009, Tüzün and Stoks 2018), and (2) a warmer region because of an increase in voltinism (Zeuss et al. 2017) and the associated increase in time stress per generation (Rowe and Ludwig 1991, Abrams et al. 1996, Shama et al. 2011). Furthermore, based on latitudinal patterns in heat tolerance and evolution of heat tolerance under warming in freshwater ectotherms (Geerts et al. 2015, Seefeldt and Ebert 2019, Sunday et al. 2019) we expected the evolution of increased heat tolerance when invading warmer regions. Because of a release from selection (Lancaster 2016; in the adult stage of the study species, Lancaster et al. [2015]), we expected no change in heat tolerance when invading cooler regions.

\section{Materials AND Methods}

\section{Study system}

Ischnura elegans (Vander Linden 1820) has a broad latitudinal range in Europe with its historical core range going from southern France to southern Sweden (Boudot and Kalkman 2015; Fig. 1A). The Pyrenees made the southern range limit and the species was historically absent in Spain where the congener I. graellsii occurs (Wellenreuther et al. 2018). In the 20th century, I. elegans showed two range expansions from southern France into Spain (Ocharán 1987, Sánchez-Guillén et al. 2013; R. A. Sánchez-Guillén, personal communication; Fig. 1A). In the 1950s, the species first expanded its range southward along the Spanish east coast and reached its most southern limit in the region of Murcia (Andreu Rubio 1953). Today, persistent populations occur along the entire Spanish east coast up to Murcia, with apparently no further expansions southward along this expansion front (Sánchez-Guillén et al. 2011, Wellenreuther et al. 2011). In the 1980s, I. elegans also 

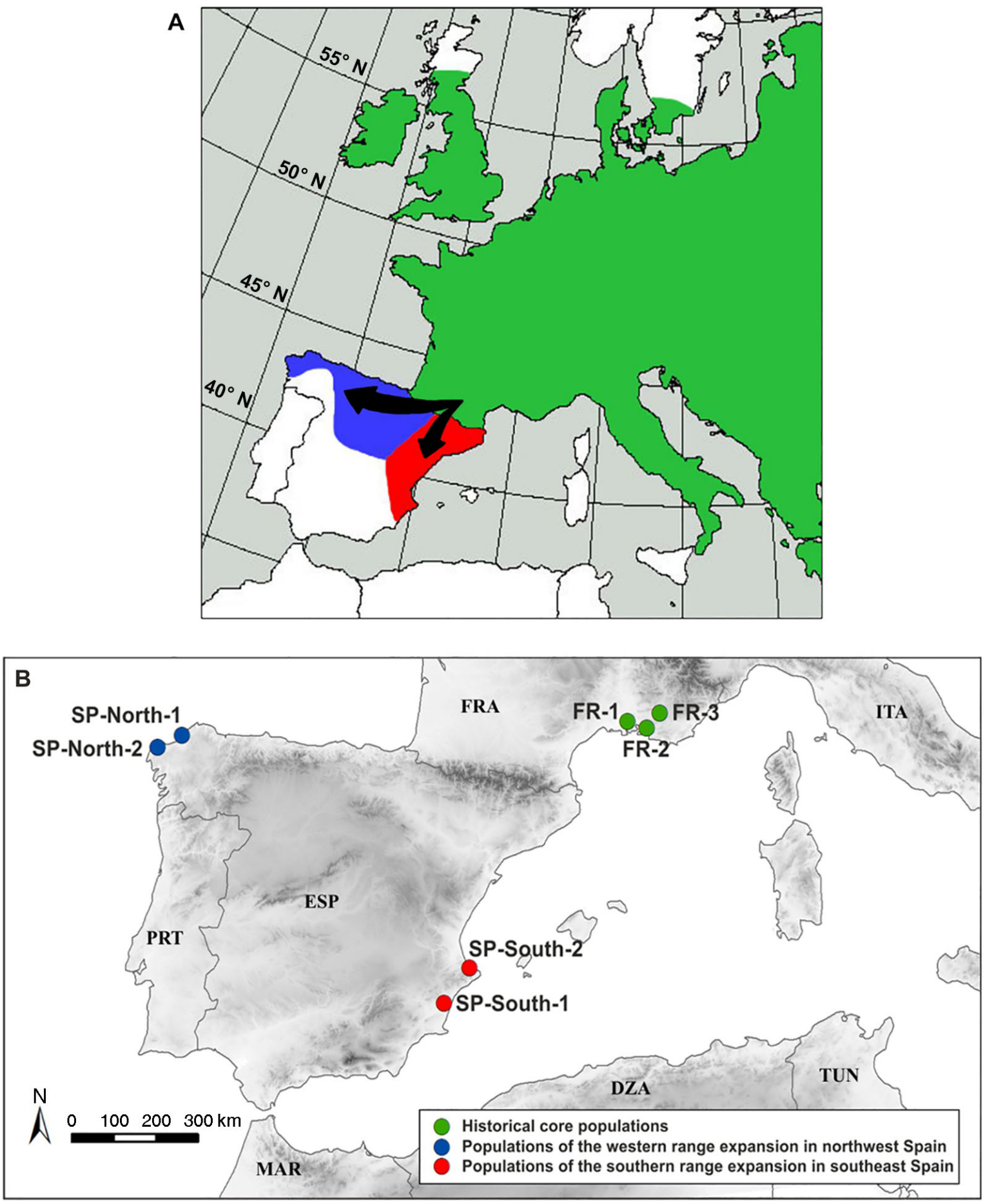

FIG. 1. (A) Historical European core range (green) with the two range expansion axes in Spain (southeast Spain, red; northwest Spain, blue) of Ischnura elegans based on Dijkstra (2006) and Sánchez-Guillén et al. (2013). (B) Location of the study populations in each of the three regions.

started expanding its range along the northwest coast of Spain (Ocharán 1987), now reaching up to south Galicia (Sánchez-Guillén et al. 2011; A. Cordero, personal observation). Based on geography, populations from southern
France are the most probable origin of the Iberian populations. Genetic studies indicate ongoing introgression with I. graellsii in the Iberian populations (Wellenreuther et al. 2011, 2018). 
Within its historical core range I. elegans shows latitude-associated thermal adaptation in larval life history, behavior, and physiology (e.g., Shama, et al. 2011, Stoks and De Block 2011, Van Dinh et al. 2013, Debecker et al. 2017, Debecker and Stoks 2019). The general pattern is that low-latitude populations (southern France) deal better with higher temperatures than high-latitude populations (southern Scandinavia) likely as a result of gradual thermal evolution after the last glaciation cycle. Changes in thermal adaptation along the contemporary range expansions outside the historical core range into Spain (Fig. 1B) have never been looked at.

To study the evolution of thermal adaptation in association with the two range expansions in Spain, we selected three regions: southern France (FR), which is within the historical core range and the most likely source of the Spanish populations, southeast Spain (SPSouth), representing the older range expansion toward a warmer region, and northwest Spain (SP-North), representing the more recent range expansion toward a cooler region. To substantiate the occurrence of range expansions toward warmer and cooler regions, we characterized the thermal regimes in summer in the three regions. We did so by performing simulations with the Lake Model Flake to estimate the long-term average summer water temperatures in the three regions (see Appendix S1 for details; Lake Model Flake available online). ${ }^{\frac{2}{2}}$ Simulations revealed an average (mean $\pm \mathrm{SE}$ ) water temperature in summer of $24.19^{\circ} \pm 0.02^{\circ} \mathrm{C}$ in the FR region, and indeed a lower mean $\left(21.69^{\circ} \pm 0.01^{\circ} \mathrm{C}\right)$ in the cooler SP-North region, and a higher mean $\left(26.81^{\circ} \pm 0.01^{\circ} \mathrm{C}\right)$ in the warmer SP-South region. The percentage of summer days with extreme water temperatures exceeding $28^{\circ} \mathrm{C}$ followed this pattern. The selected regions therefore allow us to test the evolution of thermal performance curves in association with the two independent range expansions toward a warmer (SPSouth) and a cooler (SP-North) region.

\section{Collecting and housing}

In each region, replicated populations (two each in SP-North and SP-South, three in FR) were sampled in 2017 (Fig. 1B, Appendix S1: Table S1). For each of the range expansions, we selected two populations near the edge of the range front. The species is multivoltine in the study regions (with for example, three to four generations per year in southern France). We collected eggs in June and July in SP-South and FR, and in August in SPNorth. This matches the central part of the flight season in each region, so that we collected eggs of an intermediate generation at each latitude.

In each population, 4-16 mated pairs were collected. All females showed the promontory spine, a structure located in the prothorax that is diagnostic for I. elegans and contrasts it with I. graellsii (Wellenreuther et al.

\footnotetext{
${ }_{\text {http://www.flake.igb-berlin.de }}$
}

2018). Females were placed in small plastic containers covered with mesh and given moistened filter paper as oviposition substrate. Eggs were sent to Belgium and kept at $22^{\circ} \mathrm{C}$ for hatching. To enhance survival (De Block and Stoks 2003), larvae were placed in groups of 100 in $200-\mathrm{mL}$ plastic cups at $22^{\circ} \mathrm{C}$ and fed Artemia nauplii ad libitum daily during the first ten days after hatching.

\section{Experimental design}

To investigate the effects of region and temperature on life history, physiology, and behavior, we used a full factorial design with four rearing temperatures $\left(16^{\circ}, 20^{\circ}\right.$, $24^{\circ}$, and $28^{\circ} \mathrm{C}$ ) and three regions with two to three replicated populations per region. This range of temperatures covers the natural temperature regime of the studied populations during the main part of the larval growth season. Below $16^{\circ} \mathrm{C}$, the growth rate is very low, and survival decreases considerably when larvae are reared at temperatures below $16^{\circ} \mathrm{C}$ and above $28^{\circ} \mathrm{C}$. Note that we kept the larvae for the first 10 days at the intermediate temperature of $22^{\circ} \mathrm{C}$. This is unlikely to have biased our comparison of TPCurves across regions, as 10 days is only a short period compared to the entire larval period (2-4 months). Moreover, TPCurves did not consistently peak around $22^{\circ} \mathrm{C}$ (see Results). We started the rearing experiment with 100 larvae per combination of temperature and region (total of 1,200 larvae); per temperature larvae were as equally as possible distributed among the two to three populations per region.

When larvae were 10 days old, they were placed in incubators set at $16^{\circ}, 20^{\circ}, 24^{\circ}$, and $28^{\circ} \mathrm{C}(14 \mathrm{~h}$ light : 10 $\mathrm{h}$ dark photoperiod). Each larva was reared individually in a plastic cup filled with $100 \mathrm{~mL}$ aged tap water. Cups were refilled twice a week and daily rotated within their incubator. Larvae were fed ad libitum with Artemia nauplii (224 \pm 8 nauplii per food ration [mean $\pm \mathrm{SE}$ ], $n=52$ food rations) $6 \mathrm{~d}$ per week. When larvae reached the final instar, they were fed daily to meet the greater energy demands.

\section{Response variables}

We quantified key traits related to life history (survival, development rate, growth rate), behavior (food intake), and physiology (growth efficiency, heat tolerance). Survival was calculated as the percentage of the larvae per temperature-by-region combination that survived the experiment. We estimated development rate as the inverse of the number of days from egg hatching until the molt into the final instar. We measured the growth rate during the first $7 \mathrm{~d}$ of the final instar, when most increase in body mass occurs (see Appendix S2 for details). During this 7-d growth period, we quantified food intake and growth efficiency on a subset of 30 larvae per temperature-by-region (total of 360 larvae). Details on the methods are reported in Appendix S3. 
Finally, we performed heat tolerance trials on another subset of 30 larvae (from the two to three collected populations) per temperature-by-region (total of 360 larvae) to determine the critical thermal maximum (CTmax; see Appendix S2 for details).

\section{Statistical analyses}

The effects of rearing temperature and region on the response variables (except survival) were tested using generalized linear mixed models (GLMMs) with a normal error structure and the identity link function. Survival was analyzed at the individual level (binary: dead or alive) and therefore tested using a binomial error structure and the logit link function. The effects of temperature (both linear and quadratic terms) and region (SP-South, SP-North, and FR) were tested by including these terms and their interactions as predictor variables. Population nested within region was a random factor in all models. To correct for body mass, we included the final body mass as a covariate in models for food intake and CTmax, but it was removed from both models as it was not significant (CTmax, $P=0.6667$; food intake, $P=0.2177)$. The Region $\times$ Temperature ${ }^{2}$ interaction was removed from the model for food intake as it was not significant $(P=0.1435)$. We further explored significant Temperature $\times$ Region interactions using Fisher's post hoc LSD $t$ tests with Bonferroni correction; these post hoc results are visualized in the figures. Statistical analyses were conducted using $\mathrm{R}$ version 3.5.3 for Windows ( $\mathrm{R}$ Core Team 2015), packages lme4 and lmerTest, and SPSS for Windows, v23.0. 2015 (IBM Corporation, Armonk, New York, USA).

\section{Results \\ Life history}

Survival was lowest at $16^{\circ} \mathrm{C}$ in all regions but was highest at this temperature in SP-South larvae, and increased in each region to a maximum between $20^{\circ}$ and $24^{\circ} \mathrm{C}$ (Region $\times$ Temperature, Region $\times$ Temperature ${ }^{2}$; Table 1, Fig. 2A). At $28^{\circ} \mathrm{C}$, survival remained high in SPNorth and SP-South larvae but decreased in FR larvae.

SP-South larvae consistently had the highest development rate, especially at the highest temperature of $28^{\circ} \mathrm{C}$ (Region $\times$ Temperature, $\quad$ Region $\times$ Temperature $^{2}$; Table 1, Fig. 2B). Development rates were lowest at $16^{\circ} \mathrm{C}$ and increased in each region to a maximum between $20^{\circ}$ and $24^{\circ} \mathrm{C}$ (Table 1, Fig. 2B). At $28^{\circ} \mathrm{C}$, development rate remained high at SP-South and SPNorth but decreased at FR (Region $\times$ Temperature, Region $\times$ Temperature ${ }^{2}$; Table 1, Fig. 2B).

Across temperatures, SP-North larvae consistently had the highest growth rate (main effect region; Table 1, Fig. 2C). The effects of temperature on growth rate strongly differed between regions (Region $\times$ Temperature, Region $\times$ Temperature ${ }^{2}$; Table 1, Fig. 2C). FR larvae
TABLE 1. Results of the generalized linear mixed models testing for the effects of temperature and region on the response variables. Values marked with bold indicate statistically significant $P$-values.

\begin{tabular}{|c|c|c|c|}
\hline Response variable and effect & Wald $\chi^{2}$ & $\mathrm{df}$ & $P$ \\
\hline \multicolumn{4}{|l|}{ Survival } \\
\hline Region & 6.760 & 2 & 0.0340 \\
\hline Temperature & 111.592 & 1 & $<0.0001$ \\
\hline Temperature $^{2}$ & 101.900 & 1 & $<0.0001$ \\
\hline Region $\times$ Temperature & 14.983 & 2 & 0.0005 \\
\hline Region $\times$ Temperature $^{2}$ & 16.148 & 2 & 0.0003 \\
\hline Population & $\dagger$ & 1 & 1.0000 \\
\hline \multicolumn{4}{|l|}{ Development rate } \\
\hline Region & 327.978 & 2 & $<0.0001$ \\
\hline Temperature & 280.081 & 1 & $<0.0001$ \\
\hline Temperature $^{2}$ & 229.666 & 1 & $<0.0001$ \\
\hline Region $\times$ Temperature & 12.761 & 2 & 0.0017 \\
\hline Region $\times$ Temperature $^{2}$ & 14.951 & 2 & 0.0005 \\
\hline Population & $\dagger$ & 1 & $<0.0001$ \\
\hline \multicolumn{4}{|l|}{ Growth rate } \\
\hline Region & 187.735 & 2 & $<0.0001$ \\
\hline Temperature & 9.463 & 1 & 0.0020 \\
\hline Temperature $^{2}$ & 8.176 & 1 & 0.0042 \\
\hline Region $\times$ Temperature & 15.672 & 2 & 0.0004 \\
\hline Region $\times$ Temperature ${ }^{2}$ & 18.402 & 2 & 0.0001 \\
\hline Population & $\dagger$ & 1 & 1.0000 \\
\hline \multicolumn{4}{|l|}{ Food intake } \\
\hline Region & 17.972 & 2 & 0.0001 \\
\hline Temperature & 4.939 & 1 & 0.0262 \\
\hline Temperature $^{2}$ & 7.028 & 1 & 0.0080 \\
\hline Region $\times$ Temperature & 24.456 & 2 & $<0.0001$ \\
\hline \multicolumn{4}{|l|}{ Growth efficiency } \\
\hline Region & 94.924 & 2 & $<0.0001$ \\
\hline Temperature & 0.016 & 1 & 0.0463 \\
\hline Temperature $^{2}$ & 0.002 & 1 & 0.0816 \\
\hline Region $\times$ Temperature & 12.707 & 2 & 0.0017 \\
\hline Region $\times$ Temperature ${ }^{2}$ & 13.548 & 2 & 0.0011 \\
\hline Population & $\dagger$ & 1 & 0.0636 \\
\hline \multicolumn{4}{|l|}{ CTmax } \\
\hline Region & 44.546 & 2 & $<0.0001$ \\
\hline Temperature & 3.816 & 1 & 0.0507 \\
\hline Temperature $^{2}$ & 7.831 & 1 & 0.0051 \\
\hline Region $\times$ Temperature & 6.353 & 2 & 0.0417 \\
\hline Region $\times$ Temperature $^{2}$ & 7.308 & 2 & 0.0258 \\
\hline Population & $\dagger$ & 1 & 0.2489 \\
\hline
\end{tabular}

Note: CTmax is larval heat tolerance.

${ }^{\dagger}$ Wald $\chi 2$ values are not available for random factors.

had constant growth rates across temperatures. SP-North larvae steadily increased their growth rate with increasing temperature. SP-South larvae had an inverse U-shaped thermal performance curve with maximum growth rate at $20^{\circ}$ and $24^{\circ} \mathrm{C}$, and slower growth at $16^{\circ}$ and $28^{\circ} \mathrm{C}$.

\section{Food intake and growth efficiency}

The effect of temperature on mass-corrected food intake strongly differed between regions and temperatures (Region, Temperature, Temperature ${ }^{2}$, Region $\times$ 

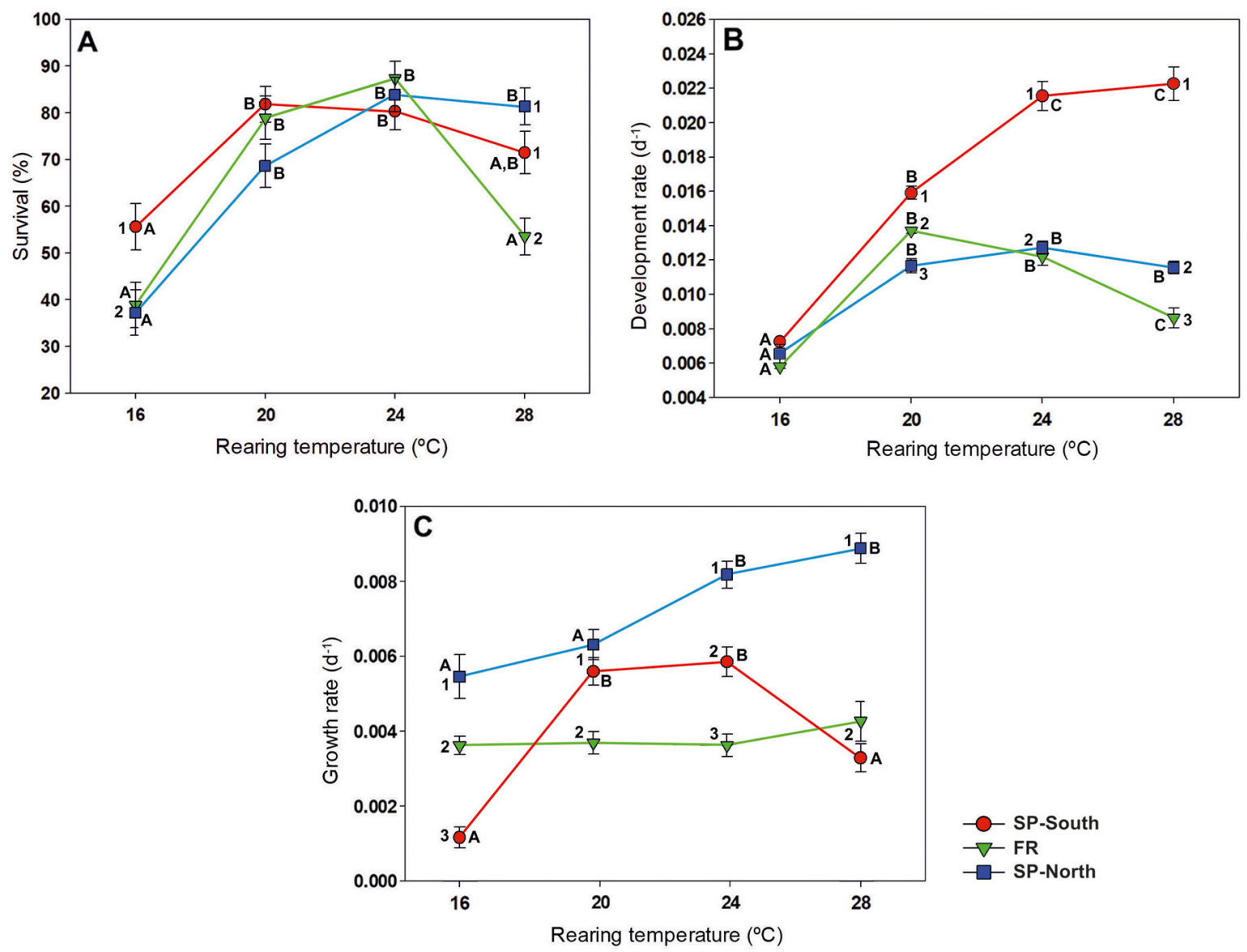

FIG. 2. Thermal performance curves for the life history variables of Ischnura elegans larvae in the three regions: (A) survival, (B) development rate, and (C) growth rate. Values are mean \pm SE. Significant differences between means are determined by Fisher's post hoc least significance difference $t$ tests with Bonferroni correction and are indicated as follows: numbers represent differences among regions at a given temperature; letters represent differences among temperatures at a given region.

Temperature; Table 1, Fig. 3A). The food intake of FR larvae increased from $16^{\circ}$ to $20^{\circ} \mathrm{C}$ and then remained constant at a high level. SP-North larvae steadily increased food intake with increasing temperature. In contrast, SP-South larvae showed a lower food intake at the higher temperatures $\left(24^{\circ}\right.$ and $28^{\circ} \mathrm{C}$; Fig. $\left.3 \mathrm{~A}\right)$. Regions did not differ in food intake at $16{ }^{\circ} \mathrm{C}$ while, at the higher temperatures $\left(24^{\circ}\right.$ and $\left.28^{\circ} \mathrm{C}\right)$, food intake was greater in FR and SP-North larvae (Fig. 3A).

Across temperatures, SP-North larvae showed the highest growth efficiency (main effect region; Table 1, Fig. 3B). Temperature affected the growth efficiency differently between regions (Region $\mathrm{x}$ Temperature, Region $\times$ Temperature ${ }^{2}$; Table 1, Fig. 3B). FR and SPNorth larvae had a constant growth efficiency across temperatures, while in SP-South larvae growth efficiency showed a maximum at $24^{\circ} \mathrm{C}$ and a minimum at $28^{\circ} \mathrm{C}$.

\section{Heat tolerance (CTmax)}

Across temperatures, SP-South larvae consistently had a greater CTmax, especially at the highest temperature of $28^{\circ} \mathrm{C}$ (main effect Region, Region $\times$ Temperature, Region $\times$ Temperature $^{2}$; Fig. 4, Table 1). While CTmax increased with increasing rearing temperature this was most pronounced in SP-South larvae, while CTmax levelled off at $24^{\circ} \mathrm{C}$ in SP-North larvae (Fig. 4).

\section{DisCUSSION}

Our results suggest evolution of the TPCurves of most traits in association with both range expansions. As expected, compared to the ancestral FR larvae, the southward range expansion to the warmer SP-South region was associated with larvae coping better with the highest rearing temperature in terms of development, and having a greater heat tolerance (CTmax). Notably, we observed that the range expansions to warmer and cooler regions resulted in partly similar evolutionary changes in the TPCurves for life history, and no opposite changes in heat tolerance. Given we worked with F1 offspring of field-collected mothers, we cannot exclude the 

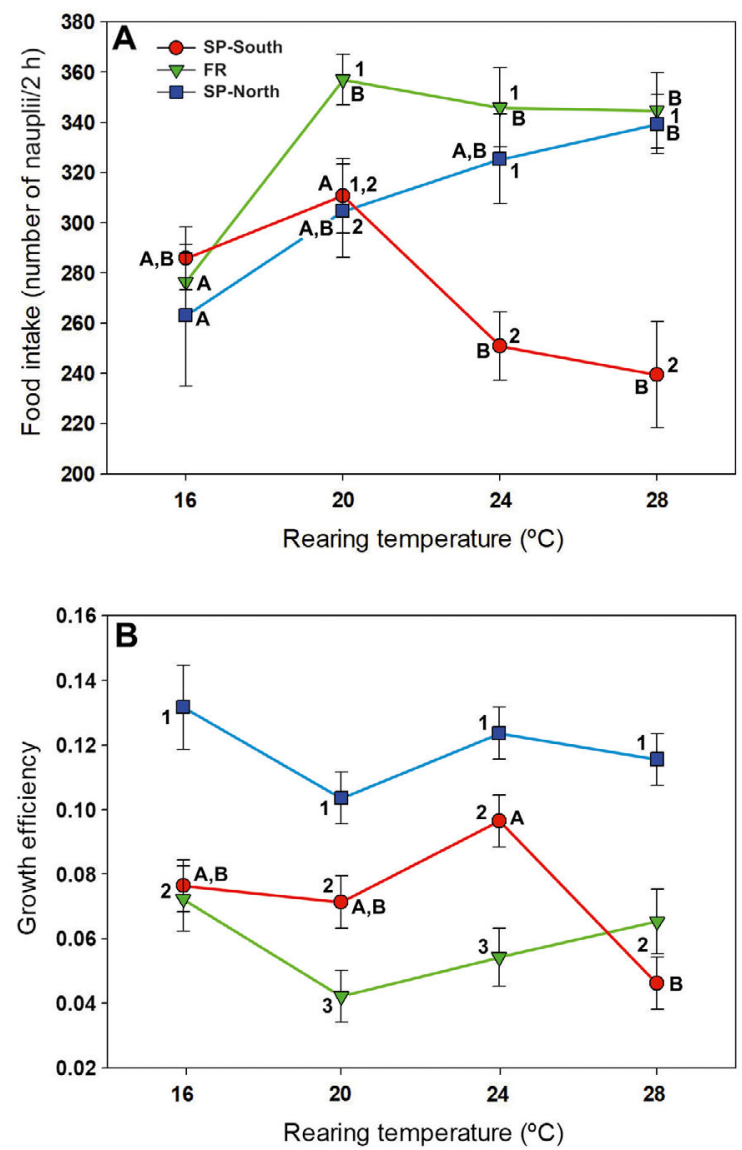

FIG. 3. Thermal performance curves for (A) food intake and (B) growth efficiency of Ischnura elegans larvae in the three regions. Values are mean \pm SE. Significant differences between mean food intake determined by Fisher's post hoc LSD $t$ test with Bonferroni correction are indicated as follows: numbers represent differences among regions at a given temperature; letters represent differences among temperatures at a given region.

possibility of maternal effects contributing to the differentiation in TPCurves. Maternal effects for early larval growth rate are small and non-significant in the study species (Shama et al. 2011), and in general become smaller throughout ontogeny (e.g., Munday et al. 2017, White and Wilson 2019), reducing its effects in our study as we scored all traits in the final larval instar. Nonetheless, maternal contributions may have complemented the evolution of TPCurves during both range expansions.

\section{Ancestral TPCurves in the FR region}

The FR populations showed thermal adaptation as survival was highest at their regional mean summer water temperature of $\sim 24^{\circ} \mathrm{C}$. In contrast, while development rates were also high at $24^{\circ} \mathrm{C}$ they were somewhat greater at $20^{\circ} \mathrm{C}$, while growth rates were remarkably constant across temperatures. Flat thermal reaction norms

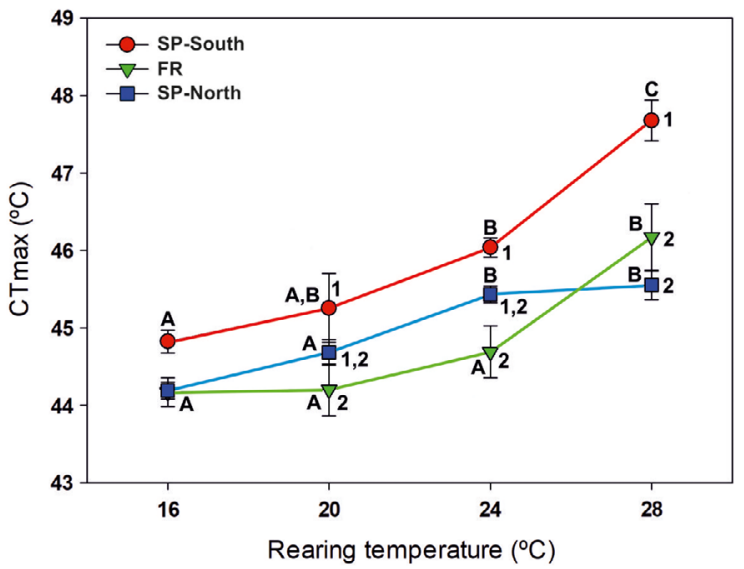

FIG. 4. Thermal performance curves for larval heat tolerance (CTmax) of Ischnura elegans larvae in the three regions. Values are mean \pm SE. Significant differences between mean CTmax determined by Fisher's post hoc LSD $t$ test with Bonferroni correction are indicated as follows: numbers represent differences among regions at a given temperature, letters represent differences among temperatures at a given region.

may occur when populations rapidly adjust their peak performance to the rearing temperature as a result of phenotypic plasticity (Rohr et al. 2018). The flat thermal growth pattern of the FR larvae was the result of a lower food intake but a greater growth efficiency at $16^{\circ} \mathrm{C}$, and a greater food intake but lower growth efficiency in the $20^{\circ}-28^{\circ} \mathrm{C}$ temperature range. As typically observed (e.g., Chown et al. 2009, Sánchez-Fernández et al. 2010, Arribas et al. 2012), the heat tolerance increased with rearing temperature, even at $28^{\circ} \mathrm{C}$. This may constitute an adaptive response to the frequent occurrence of heat waves in the FR region. Yet, this pattern may also be explained by the shorter exposure times in the CTmax test in larvae reared at higher temperatures, as we started the CTmax test at the rearing temperature of the larvae (see Appendix S2). Note that the observed CTmax values of $44^{\circ} \mathrm{C}$ and higher are above those encountered in the natural populations, a typical pattern for CTmax values (e.g., Jørgensen et al. 2019). Nevertheless, CTmax values are highly correlated with maximum environmental temperatures thereby being a good proxy of the relative ability to deal with thermal extremes across groups of animals (e.g., Huey et al. 2012; Jørgensen et al. 2019).

\section{Evolution during the range expansion to the cooler SP- North region}

The SP-North populations most strikingly differed from the ancestral FR populations in their consistently greater growth rates. This matches a pattern of countergradient variation, where genotypes code for greater growth rates in colder environments (here colder water bodies) to buffer the negative 
environmental influence on growth rate (Conover et al. 2009). These countergradient patterns in phenotypic traits may rapidly evolve, as recently documented for growth rate along urbanization gradients in the damselfly Coenagrion puella (Tüzün et al. 2017), and for flowering time in common ragweed Ambrosia artemisiifolia (Gorton et al. 2018). Similar to our study, mosquitofish developed a pattern of countergradient variation for metabolic rate within a period of $100 \mathrm{yr}$ along invasion fronts in two continents (Moffett et al. 2018). The faster growth of the SP-North compared to the FR populations was mainly realized through a greater growth efficiency across temperatures. In addition, at $20^{\circ} \mathrm{C}$ also the food intake was greater. Similarly, the evolution of a faster growth during the range expansion of the butterfly Euphydryas phaeton was associated with a greater growth efficiency (Bowers et al. 1992).

Unexpectedly, the edge populations in the cooler SPNorth region also had a higher survival, development rate and growth rate at $28^{\circ} \mathrm{C}$ compared to the ancestral FR populations. The greater development and growth rates at $28^{\circ} \mathrm{C}$ resemble the pattern observed in Coenagrion damselflies where populations at colder, high latitudes increased their growth rate more under warming than those at warmer, low latitudes (NilssonÖrtman et al. 2012). This resulted in optimal temperatures for performance traits being higher than the mean environmental temperature. This widespread pattern (e.g., Van Doorslaer and Stoks 2005) has been explained, among others, as a strategy to reduce the risk of experiencing the strong negative effects of exposure to temperatures above the optimal temperature (Martin and Huey 2008).

The SP-North population did not evolve a lower heat tolerance when invading the cooler region. Yet, while CTmax increased going from $24^{\circ}$ to $28^{\circ} \mathrm{C}$ in the FR population, it levelled off at $28^{\circ} \mathrm{C}$ in the SPNorth population. This may suggest ongoing evolution toward a lower CTmax that has not yet resulted in a significant reduction in CTmax at $28^{\circ} \mathrm{C}$, possibly because of the recent origin of this expansion (1980s; Ocharán 1987). A reduction of CTmax may be expected in the SP-North populations where extreme summer temperatures are very rare, and because of an energy-mediated trade-off between CTmax and fast growth (Roze et al. 2013). Note this pattern cannot be an artefact of different exposure times in the CTmax test depending on the rearing temperature as here we contrast CTmax at the same rearing temperature between regions. Notably, a similar pattern of no change in upper thermal tolerance has been described during the ongoing northward expansion of I. elegans to colder regions in Sweden (Lancaster et al. 2015). This fits the general pattern that during northward range expansions to cooler areas species tend to keep their greater thermal tolerance (Lancaster 2016).

\section{Evolution during the range expansion to the warmer $S P$ - South region}

During the southward range expansion to the warmer SP-South region, the SP-South larvae evolved a greater ability to survive at the highest rearing temperature $\left(28^{\circ} \mathrm{C}\right)$ and a greater heat tolerance (especially at $28^{\circ} \mathrm{C}$ ). Note again, this heat tolerance pattern cannot be an artifact of shorter exposure times in the CTmax test for larvae reared at $28^{\circ} \mathrm{C}$ as it contrasts SP-South and FR larvae reared at $28^{\circ} \mathrm{C}$. This evolution of a higher heat tolerance can be explained by the higher percentage of extreme $\left(>28^{\circ} \mathrm{C}\right)$ summer days in SP-South compared to FR. The evolution of heat tolerance has only rarely been documented in the context of contemporary range expansions. Notable examples are the rapid evolution of a greater heat tolerance in natural populations of the water flea Daphnia magna (Brans et al. 2017) and the ant Temnothorax curvispinosus (Martin et al. 2019) when invading urban heat islands.

In addition, SP-South larvae evolved the highest development rate at $28^{\circ} \mathrm{C}$. This likely reflects evolution of a greater voltinism, hence the completion of more generations per year in the SP-South populations. Within its historical core range I. elegans shows a latitudinal cline going from one generation every two years at the cooler, high latitudes toward three to four generations per year in the warmer FR region (Corbet et al. 2006). A further increase in voltinism in the warmer FR region would be a logical extension of this widespread latitudinal cline in insects (Zeuss et al. 2017) and matches the pattern that species increase voltinism under global warming (Matsuda et al. 2018). Notably, the faster development was at $20^{\circ} \mathrm{C}$ and $24^{\circ} \mathrm{C}$ accompanied by faster growth compared to the FR populations, which may reflect compensatory growth responses to avoid large size reductions when larval growth periods become shorter (as also occurs in FR populations compared to high-latitude populations; Shama et al. 2011, Debecker and Stoks 2019). The increased growth rates at $20^{\circ}$ and $24^{\circ} \mathrm{C}$ were realized through a greater growth efficiency and despite a lower food intake compared to the FR larvae. At the highest rearing temperature, where the same high development rate occurred as at $24^{\circ} \mathrm{C}$, growth rate was, however, lower and not different from the FR populations. Possibly, at $28^{\circ} \mathrm{C}$ this is the result of an energymediated trade-off where the larvae prioritize the strong increase in CTmax over a fast growth (Roze et al. 2013).

\section{Conclusions and Future Directions}

While there are increasing reports of range expansions in other than poleward directions (Lenoir and Svenning 2015), these have been much less studied. Studying the evolution of trait means and their plasticity during contemporary range expansions is considered pivotal to predict future range expansions (Valladares et al. 2014, Bush et al. 2016, Diamond 2018). We found 
indications of evolution of TPCurves, including both the trait means and their plasticity, for life history, behavior, and physiology in association with both the range expansions toward warmer and cooler regions. While not the focus of current study, an intriguing possibility that needs formal testing is that, besides selection on standing genetic variation and de novo mutations, also introgression of adaptive alleles of $I$. graellsii (e.g., linked to heat tolerance), may have contributed to this evolution (Sánchez-Guillén et al. 2016, Wellenreuther et al. 2018). Irrespective of the underlying genetic mechanisms, a key finding of our study was that range expansions to warmer and cooler regions resulted in partly similar evolutionary changes in the TPCurves for life history, and no opposite changes in heat tolerance. Notably, we could not only show adaptive evolution of heat tolerance, a key range-limiting trait in aquatic ectotherms (Sunday et al. 2012), toward greater mean values but also of its plastic response to warming during the southward range expansion. Yet, our results also suggest that plasticity in heat tolerance alone is inadequate to adapt to new thermal regimes, thereby complementing the inability of plasticity in heat tolerance to provide complete compensation for global warming in situ (Gunderson et al. 2017).

\section{ACKNOWLEDGMENTS}

J. A. Carbonell and R. Stoks are joint first authors. We thank Ria Van Houdt, Rony Van Aerschot, and Geert Neyens for technical support. Julie Verheyen, Vienna Delnat, María Botella, Andrés Millán, Josefa Velasco, Félix Picazo, and Adolfo Cordero assisted with egg collection. Rosa Ana Sánchez-Guillén and Adolfo Cordero provided valuable information on populations. Comments from two anonymous reviewers improved the manuscript. J. A. Carbonell currently is a postdoctoral researcher funded by the Juan de la Cierva-Formación program (FJCI-2017-31709) by the Spanish Ministry of Economy, Industry and Competitiveness. This work was supported by the Fund for Scientific Research Flanders (FWO, G.0524.17N and G.0956.19N) and the KU Leuven (C16/17/ 002). Permits for fieldwork were granted by the Direcció General de Medi Natural i d'Avaluació Ambiental (Generalitat Valenciana) (ref: 322/17(FAU17_028)) and the Spanish Ministry of Economy and Business (project ref: CGL2014-53140-P).

\section{Literature Cited}

Abrams, P. A., O. Leimar, S. Nylin, and C. Wiklund. 1996. The effect of flexible growth rates on optimal sizes and development times in a seasonal environment. American Naturalist 147:381-395.

Andrade-Restrepo, M., N. Champagnat, and R. Ferrière. 2019. Local adaptation, dispersal evolution, and the spatial ecoevolutionary dynamics of invasion. Ecology Letters 22:767777.

Andreu Rubio, J. M. 1953. Los insectos Odonatos en la provincia de Murcia. Volume 15. Publicaciones de la Universidad de Murcia, Murcia, Spain.

Arribas, P., J. Velasco, P. Abellán, D. Sánchez-Fernández, C. Andújar, P. Calosi, A. Millán, I. Ribera, and D. Bilton. 2012. Dispersal ability rather than ecological tolerance drives differences in range size between lentic and lotic water beetles
(Coleoptera: Hydrophilidae). Journal of Biogeography 39:984-994.

Boudot, J. P. and V. J. Kalkman, Editors. 2015. Atlas of the European dragonflies and damselflies. KNNV Publishing, The Netherlands.

Bowers, M. D., N. E. Stamp, and S. K. Collinge. 1992. Early stage of host range expansion by a specialist herbivore, Euphydryas phaeton (Nymphalidae). Ecology 73:526-536.

Brans, K. I., M. Jansen, J. Vanoverbeke, N. Tüzün, R. Stoks, and L. De Meester. 2017. The heat is on: Genetic adaptation to urbanization mediated by thermal tolerance and body size. Global Change Biology 23:5218-5227.

Bush, A., K. Mokany, R. Catullo, A. Hoffmann, V. Kellermann, C. Sgrò, S. McEvey, and S. Ferrier. 2016. Incorporating evolutionary adaptation in species distribution modelling reduces projected vulnerability to climate change. Ecology Letters 19:1468-1478.

Chen, I. C., J. K. Hill, R. Ohlemüller, D. B. Roy, and C. D. Thomas. 2011. Rapid range shifts of species associated with high levels of climate warming. Science 333:1024-1026.

Chown, S. L., K. R. Jumbam, J. G. Sørensen, and J. S. Terblanche. 2009. Phenotypic variance, plasticity and heritability estimates of critical thermal limits depend on methodological context. Functional Ecology 23:133-140.

Conover, D. O., T. A. Duffy, and L. A. Hice. 2009. The covariance between genetic and environmental influences across ecological gradients. Annals of the New York Academy of Sciences 1168:100-129.

Corbet, P. S., F. Suhling, and D. Soendgerath. 2006. Voltinism of Odonata: a review. International Journal of Odonatology 9:1-44.

Crozier, L. 2004. Warmer winters drive butterfly range expansion by increasing survivorship. Ecology 85:231-241.

De Block, M., and R. Stoks. 2003. Adaptive sex-specific life history plasticity to temperature and photoperiod in a damselfly. Journal of Evolutionary Biology 16:986-995.

Debecker, S., K. V. Dinh, and R. Stoks. 2017. Strong delayed interactive effects of metal exposure and warming: latitudedependent synergisms persist across metamorphosis. Environmental Science and Technology 54:2409-2417.

Debecker, S., and R. Stoks. 2019. Pace of life syndrome under warming and pollution: integrating life history, behavior, and physiology across latitudes. Ecological Monographs 89: e01332.

Diamond, S. E. 2018. Contemporary climate-driven range shifts: Putting evolution back on the table. Functional Ecology 32:1652-1665.

Dijkstra, K.-D.- B., editor. 2006. Field guide to the dragonflies of Britain and Europe. British Wildlife Publishing, Totnes, UK.

Dudaniec, R. Y., C. J. Yong, L. T. Lancaster, E. I. Svensson, and B. Hansson. 2018. Signatures of local adaptation along environmental gradients in a range-expanding damselfly (Ischnura elegans). Molecular Ecology 27:2576-2593.

Eckhart, V. M., M. A. Geber, and C. M. McGuire. 2004. Experimental studies of adaptation in Clarkia xantiana. I. Sources of trait variation across a subspecies border. Evolution 58:59-70.

Geerts, A. N., J. Vanoverbeke, B. Vanschoenwinkel, W. Van Doorslaer, H. Feuchtmayr, D. Atkinson, B. Moss, T. A. Davidson, C. D. Sayer, L. De Meester. 2015. Rapid evolution of thermal tolerance in the water flea Daphnia. Nature Climate Change 5:665-668.

Gorton, A. J., D. A. Moeller, and P. Tiffin. 2018. Little plant, big city: a test of adaptation to urban environments in common ragweed (Ambrosia artemisiifolia). Proceedings of the Royal Society B 285:20180968. 
Gunderson, A. R., M. E. Dillon, and J. H. Stillman. 2017. Estimating the benefits of plasticity in ectotherm heat tolerance under natural thermal variability. Functional Ecology 31:1529-1539.

Huey, R. B., M. R. Kearney, A. Krockenberger, J. A. Holtum, M. Jess, and S. E. Williams. 2012. Predicting organismal vulnerability to climate warming: roles of behaviour, physiology and adaptation. Philosophical Transactions of the Royal Society of London B 367:1665-1679.

Janssens, L., and R. Stoks. 2018. Rapid larval development under time stress reduces adult life span through increasing oxidative damage. Functional Ecology 32:1036-1045.

Jørgensen, L. B., H. Malte, and J. Overgaard. 2019. How to assess Drosophila heat tolerance: unifying static and dynamic tolerance assays to predict heat distribution limits. Functional Ecology 33:629-642.

Kelly, P. W., D. W. Pfennig, S. de la Serna Buzón, and K. S. Pfennig. 2019. Male sexual signal predicts phenotypic plasticity in offspring: implications for the evolution of plasticity and local adaptation. Philosophical Transactions of the Royal Society B 374:20180179.

Kolbe, J. J., M. Kearney, and R. Shine. 2010. Modeling the consequences of thermal trait variation for the cane toad invasion of Australia. Ecological Applications 20:2273-2285.

Lancaster, L. T. 2016. Widespread range expansions shape latitudinal variation in insect thermal limits. Nature Climate Change 6:618.

Lancaster, L. T., R. Y. Dudaniec, B. Hansson, and E. I. Svensson. 2015. Latitudinal shift in thermal niche breadth results from thermal release during a climate-mediated range expansion. Journal of Biogeography 42:1953-1963.

Lee-Yaw, J. A., R. D. Zenni, K. A. Hodgins, B. M. Larson, R. Cousens, and B. L. Webber. 2019. Range shifts and local adaptation: integrating data and theory towards a new understanding of species' distributions in the Anthropocene. New Phytologist 221:644-647.

Lenoir, J., and J. C. Svenning. 2015. Climate-related range shifts-a global multidimensional synthesis and new research directions. Ecography 38:15-28.

Levins, R. 1968. Evolution in changing environments: some theoretical explorations (No. 2). Princeton University Press, Princeton, New Jersey, USA.

Levins, R. 1969. Thermal acclimation and heat resistance in Drosophila species. American Naturalist 103:483-499.

Lind, M. I., and F. Johansson. 2011. Testing the role of phenotypic plasticity for local adaptation: growth and development in time-constrained Rana temporaria populations. Journal of Evolutionary Biology 24:2696-2704.

Martin, R. A., L. D. Chick, A. R. Yilmaz, and S. E. Diamond. 2019. Evolution, not transgenerational plasticity, explains the adaptive divergence of acorn ant thermal tolerance across an urban-rural temperature cline. Evolutionary Applications 12:1678-1687.

Martin, T. L., and R. B. Huey. 2008. Why "suboptimal" is optimal: Jensen's inequality and ectotherm thermal preferences. American Naturalist 171:102-118.

Matsuda, N., K. Tanaka, Y. Watari, Y. Shintani, S. G. Goto, T. Nisimura, Y. Izumi, and H. Numata. 2018. Northward expansion of the bivoltine life cycle of the cricket over the last four decades. Global Change Biology 24:5622-5628.

Moffett, E. R., D. C. Fryxell, E. P. Palkovacs, M. T. Kinnison, and K. S. Simon. 2018. Local adaptation reduces the metabolic cost of environmental warming. Ecology 99:2318 2326.

Munday, P. L., J. M. Donelson, and J. A. Domingos. 2017. Potential for adaptation to climate change in a coral reef fish. Global Change Biology 23:307-317.
Nadeau, C. P., and M. C. Urban. 2019. Eco-evolution on the edge during climate change. Ecography 42:1280-1297. https://doi.org/10.1111/ecog.04404

Nilsson-Örtman, V., R. Stoks, M. De Block, and F. Johansson. 2012. Generalists and specialists along a latitudinal transect: patterns of thermal adaptation in six species of damselflies. Ecology 93:1340-1352.

Ocharán, F. J. 1987. Los odonatos de Asturias y de España. Aspectos sistemáticos y faunísticos, Thesis. Universidad de Oviedo, Oviedo, Spain.

Parkash, R., S. Ramniwas, and B. Kajla. 2013. Climate warming mediates range shift of two differentially adapted stenothermal Drosophila species in the Western Himalayas. Journal of Asia-Pacific Entomology 16:147-153.

R Core Team. 2015. R: a language and environment for statistical computing. R Foundation for Statistical Computing, Vienna, Austria.

Rohr, J. R., D. J. Civitello, J. M. Cohen, E. A. Roznik, B. Sinervo, and A. I. Dell. 2018. The complex drivers of thermal acclimation and breadth in ectotherms. Ecology Letters 21:1425-1439.

Rowe, L., and D. Ludwig. 1991. Size and timing of metamorphosis in complex life cycles: time constraints and variation. Ecology 72:413-427.

Roze, T., F. Christen, A. Amerand, and G. Claireaux. 2013. Trade-off between thermal sensitivity, hypoxia tolerance and growth in fish. Journal of Thermal Biology 38:98-106.

Sánchez-Fernández, D., P. Calosi, A. Atfield, P. Arribas, J. Velasco, J. Spicer, A. Millán, and D. T. Bilton. 2010. Reduced salinities compromise the thermal tolerance of hypersaline specialist diving beetles. Physiological Entomology 35:265273.

Sánchez-Guillén, R. A., A. Córdoba-Aguilar, B. Hansson, J. Ott, and M. Wellenreuther. 2016. Evolutionary consequences of climate-induced range shifts in insects. Biological Reviews 91:1050-1064.

Sánchez-Guillén, R. A., B. Hansson, M. Wellenreuther, E. I. Svensson, and A. Cordero-Rivera. 2011. The influence of stochastic and selective forces in the population divergence of female colour polymorphism in damselflies of the genus Ischnura. Heredity 107:513-522.

Sánchez-Guillén, R. A., J. Muñoz, G. Rodríguez-Tapia, T. P. F. Arroyo, and A. Córdoba-Aguilar. 2013. Climate-induced range shifts and possible hybridization consequences in insects. PLoS ONE 8:e80531.

Seefeldt, L., and D. Ebert. 2019. Temperature- versus precipitation-limitation shape local temperature tolerance in a Holarctic freshwater crustacean. Proceedings of the Royal Society B 286:20190929.

Shama, L. N., M. Campero-Paz, K. Wegner, M. De Block, and R. Stoks. 2011. Latitudinal and voltinism compensation shape thermal reaction norms for growth rate. Molecular Ecology 20:2929-2941.

Sherpa, S., M. G. Blum, and L. Després. 2019. Cold adaptation in the Asian tiger mosquito's native range precedes its invasion success in temperate regions. Evolution 73:1793-1808.

Stoks, R., and M. De Block. 2011. Rapid growth reduces cold resistance: evidence from latitudinal variation in growth rate, cold resistance and stress proteins. PLoS ONE 6:e16935.

Sunday, J. M., A. E. Bates, and N. K. Dulvy. 2012. Thermal tolerance and the global redistribution of animals. Nature Climate Change 2:686.

Sunday, J., J. M. Bennett, P. Calosi, S. Clusella-Trullas, S. Gravel, A. L. Hargreaves, F. P. Leiva, W. C. E. P. Verberk, M. Á. Olalla-Tárraga, and I. Morales-Castilla. 2019. Thermal tolerance patterns across latitude and elevation. Philosophical Transactions of the Royal Society B 374:20190036. 
Thompson, L. M., T. M. Faske, N. Banahene, D. Grim, S. J. Agosta, D. Parry, P. C. Tobin, D. M. Johnson, and K. L. Grayson. 2017. Variation in growth and developmental responses to supraoptimal temperatures near latitudinal range limits of gypsy moth Lymantria dispar (L.), an expanding invasive species. Physiological Entomology 42:181-190.

Tüzün, N., L. Op de Beeck, K. I. Brans, L. Janssens, and R. Stoks. 2017. Microgeographic differentiation in thermal performance curves between rural and urban populations of an aquatic insect. Evolutionary Applications 10:1067-1075.

Tüzün, N., and R. Stoks. 2018. Evolution of geographic variation in thermal performance curves in the face of climate change and implications for biotic interactions. Current Opinion in Insect Sciences 29:78-84.

Valladares, F. et al 2014. The effects of phenotypic plasticity and local adaptation on forecasts of species range shifts under climate change. Ecology Letters 17:1351-1364.

van Boheemen, L. A., D. Z. Atwater, and K. A. Hodgins. 2019. Rapid and repeated local adaptation to climate in an invasive plant. New Phytologist 222:614-627.

Van der Have, T. M., and G. De Jong. 1996. Adult size in ectotherms: temperature effects on growth and differentiation. Journal of Theoretical Biology 183:329-340.
Van Dinh, K., L. Janssens, S. Debecker, M. Jonge, P. Lambret, V. Nilsson-Örtman, L. Bervoets, and R. Stoks. 2013. Susceptibility to a metal under global warming is shaped by thermal adaptation along a latitudinal gradient. Global Change Biology 19:2625-2633.

Van Doorslaer, W., and R. Stoks. 2005. Growth rate plasticity to temperature in two damselfly species differing in latitude: contributions of behaviour and physiology. Oikos 111:599-605.

Wellenreuther, M., J. Muñoz, J. R. Chávez-Ríos, B. Hansson, A. Cordero-Rivera, and R. A. Sánchez-Guillén. 2018. Molecular and ecological signatures of an expanding hybrid zone. Ecology and Evolution 8:4793-4806.

Wellenreuther, M., R. A. Sánchez-Guillén, A. Cordero-Rivera, E. I. Svensson, and B. Hansson. 2011. Environmental and climatic determinants of molecular diversity and genetic population structure in a coenagrionid damselfly. PLoS ONE 6: e20440.

White, S. J., and A. J. Wilson. 2019. Evolutionary genetics of personality in the Trinidadian guppy I: maternal and additive genetic effects across ontogeny. Heredity 122:1.

Zeuss, D., S. Brunzel, and R. Brandl. 2017. Environmental drivers of voltinism and body size in insect assemblages across Europe. Global Ecology and Biogeography 26:154-165.

SUPPORTING INFORMATION

Additional supporting information may be found in the online version of this article at http://onlinelibrary.wiley.com/doi/ 10.1002/ecy.3134/suppinfo 